\title{
Perancangan Sistem Informasi Parkir dengan WiFi Berbasis Arduino
}

\author{
Novi Yulianto ${ }^{\mathrm{a}}$, Fahraini Bacharuddina2 \\ aUniversitas Mercu Buana \\ JI. Meruya Selatan No.1, DKI Jakarta, Indonesia \\ 1yulianto.on24@gmail.com \\ fahraini@gmail.com
}

\begin{abstract}
Abstrak
Sekarang ini kebutuhan akan akses informasi sangat penting karena informasi yang diperoleh tersebut dapat menentukan atau memberikan kenyamanan dan kemudahan dalam melakukan aktivitas sehari-hari. Salah satu contohnya adalah dengan menggunakan gadget seperti smartphone, notebook, tablet dan yang lain-lain, kita dapat mudah mengetahui informasi yang ada secara langsung tanpa harus datang ke tempat tersebut. Sistem ini bertujuan merancang sistem informasi di tempat parkir. Teknologi ini dapat memberikan gambaran mengenai jumlah ketersediaan tempat parkir yang sudah terisi maupun yang masih kosong. Dengan mengakses IP address yang diberikan sebelumnya, maka kita akan mengetahui ketersediaan tempat parkir secara langsung. Dari hasil pengujian dapat dikatakan bahwa sistem ini memiliki kelebihan mudah digunakan, penerapan yang sederhana dan dapat membantu meningkatkan kenyamanan/kemudahan bagi pengguna tempat parkir. Namun juga sistem ini memiliki kelemahan yaitu web server yang digunakan memiliki memori yang sangat kecil sehingga tidak dapat di akses oleh banyak pengguna dalam waktu bersamaan.
\end{abstract}

Kata kunci: tempat, parkir, otomatis, web server, microcontroller, wido

\begin{abstract}
Now the need for access to information is very important because the information obtained can specify or provide comfort and ease in performing daily activities. One example is to use gadgets such as smartphones, notebooks, tablets and others, we can easily find out information directly without having to come to the venue. This system aims to design information systems in the parking lot. This technology can provide an idea of the amount of available parking spots has been filled or empty. By accessing the IP address given earlier, then we will know the availability of parking space directly. From the test results, it can be said that this system has the advantages of easy to use, the application is simple and can help improve the comfort / convenience for users of the car park. But this system also has the disadvantage of a webserver which is used has a very small memory that can not be accessed by many concurrent users in one time.
\end{abstract}

Keywords: automatic, parking, webserver, microcontroller, wido

\section{Pendahuluan}

Di masa depan diperkirakan segala sesuatunya terhubung secara elektronik. Manusia yang terhubung dengan manusia lainnya melalui sarana internet seperti facebook, Path dan lain-lain. Selain itu manusia juga terhubung dengan seluruh peralatan elektroniknya via gadget seperti Smartphone, notebook, tablet, dan yang lain-lain. Salah satu masalah yang ada dalam kehidupan manusia modern adalah adanya kebutuhan akan tempat parkir otomatis yang dapat memberikan informasi mengenai keadaan tempat parkir di suatu gedung dengan bantuan internet. 
Tidak mudah mencari informasi ruangan parkir yang kosong pada suatu area parkir tersebut di suatu pusat perbelanjaan atau perkantoran, sering kali pengunjung atau karyawan mengalami kesulitan ketika hendak memarkirkan kendaraannya. Penyebabnya adalah kekurangan informasi area mana yang masih kosong ataupun yang sudah terisi. Hal ini mengakibatkan pengunjung berputar-putar terdahulu untuk mendapatkan area parkir yang kosong sehingga waktu berkunjung menjadi berkurang, kenyamanan menjadi berkurang, menghabiskan energi dan bahan bakar.

Dalam penelitian ini Penulis berusaha untuk mengembangkan suatu sistem yang secara otomatis dapat melakukan monitoring untuk memastikan ketersediaan tempat parkir di suatu gedung via web internet. Pengembangan teknologi tempat parkir otomatis banyak yang telah di kembangkan, namun yang membuat perbedaan adalah teknologi yang digunakan pada penelitian ini. Teknologi otomatisasi yang digunakan adalah menggunakan microcontroller dengan platform Arduino Uno yang berbasis open source [1]. Dengan menggunakan teknologi ini keadaan tempat parkir dapat dengan mudah di-monitoring baik jumlah tempat parkir yang tersedia maupun posisi tempat parkir yang masih kosong.

\section{Metodologi Penelitian}

Sistem yang telah dibangun, secara garis besar terdiri dari blok rangkaian seperti terlihat pada gambar di bawah ini:

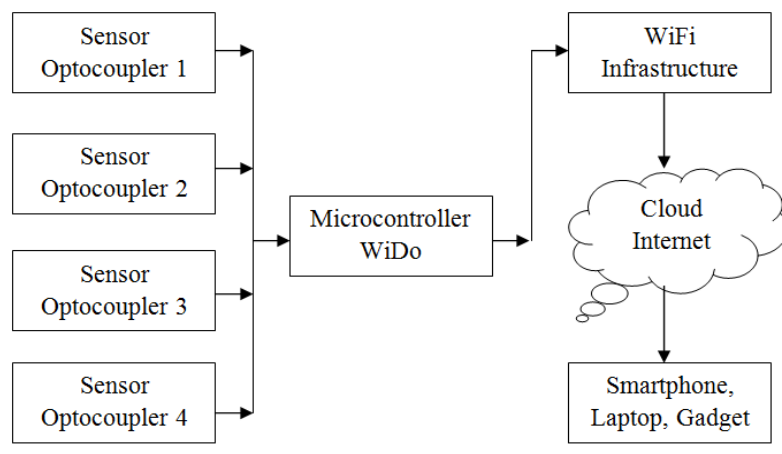

Gambar 1. Blok rangkaian Wireless Microcontoller Web server

Secara garis besar, cara kerja sistem ini adalah:

a. WiFi Infrastructure akan menghasilkan jaringan WiFi dengan sistem DHCP, yang akan memudahkan sebuah perangkat baru terhubung dengan pengaturan IP otomatis.

b. Module sensor optocoupler berfungsi untuk dapat memberikan informasi mengenai kondisi parkiran mobil, apakah terisi atau masih kosong [2].

c. Smartphone pengguna akan masuk ke dalam jaringan infrastructure dan mendapatkan IP otomatis, kemudian dengan mengetik alamat web server microcontroller WiDo melalui browser, pengguna mampu untuk melihat keadaan tempat parkiran mobil.

d. Microcontroller WiDo akan menghasilkan output berupa web server sebagai interface pengguna, kemudian microcontroller juga akan memproses data tempat parkiran mobil [3].

e. Pada web server microcontroller WiDo akan mengubah data digital mengenai kondisi suhu menjadi objek / tulisan, dimana objek tersebut merupakan sesuatu yang dapat dimengerti oleh manusia yang menerangkan ada atau tidaknya mobil yang sedang berada di parkiran tersebut.

f. Pengguna akan melakukan akses sistem parkir dengan melalui Cloud intemet. Cloud internet adalah jaringan internet dari seluruh dunia, dinamakan cloud karena pengguna dapat melakukan akses ke sistem parkir ini tanpa diketahui dimana posisinya. 


\section{Kajian Pustaka}

\subsection{Microcontroller WiDo}

Microcontroller WiDo adalah sebuah Microcontroller pengembangan berbasis Arduino Leonardo. Microcontroller WiDo dibuat sebagai solusi dari mahalnya sebuah sistem wireless berbasis Microcontroller Arduino. Dengan menggunakan Microcontroller WiDo biaya yang dikeluarkan untuk membangun sistem WiFi berbasis Microcontroller sangat murah, hanya setengah dari biaya yang dikeluarkan apabila membangun sistem WiFi dengan menggunakan Microcontroller Arduino Uno dan WiFi Shield.

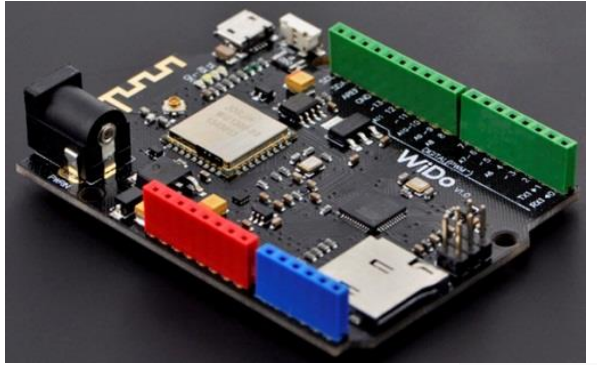

Gambar 2. Microcontroller WiDo

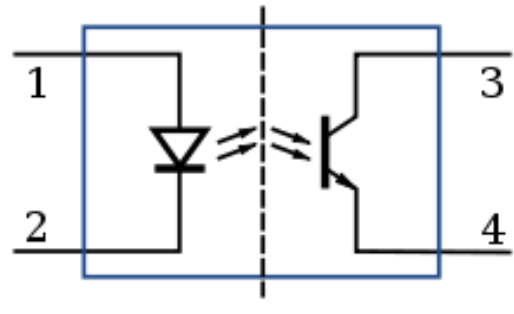

Gambar 3. Simbol Optocoupler

Microcontroller ini merupakan pengembangan dari Microcontroller Arduino Leonardo, namun yang berbeda pada Microcontroller ini memiliki tambahan yaitu berupa fitur SDCard dan WiFi. Pada Microcontroller Arduino Uno memiliki 2 buah chipset yang digunakan sebagai otak kerja platform tersebut. Beberapa chipset pada Microcontroller ini adalah:

a. Chipset ATmega32U4

ATmega32U4 adalah chipset Microcontroller 8-bit berbasis arsitektur AVR-RISC [4]. Memiliki flash Memory ISP sebesar 32 KB yang dapat dibaca-tulis. 1024 Byte EEPROM, 2,5 KByte SRAM, 32 register, 2 buah counter, dan interrupt untuk internal dan eksternal. Untuk berkomunikasi ATmega dilengkapi dengan USART dan Serial port SPI. ATmega32U4 juga dilengkapi dengan USB Transceiver sehingga memudahkan komunikasi dengan komputer. Chipset ini memiliki pin 20 input digital output (yang 7 dapat digunakan sebagai output PWM dan 12 input analog). Chipset ini memiliki komunikasi USB yang dibuat secara built-in, sehingga menghilangkan kebutuhan untuk prosesor sekunder. Hal ini memungkinkan Microcontroller ini tampil di komputer dan terhubung sebagai mouse dan keyboard. Chipset ini juga memungkinkan untuk serial (CDC) komunikasi melalui USB dan muncul sebagai com port virtual sebagai perangkat lunak pada komputer. Chipset ini memiliki standar kecepatan USB 2.0 dan menggunakan driver standar USB COM pada windows.

b. Chipset WG1300 WiFi

WG1300-B0 adalah modul WLAN 2.4GHz yang dapat diintegrasikan dengan biaya murah / daya MCU rendah untuk membuat solusi ideal untuk aplikasi embedded [5]. WG1300-B0 dapat mendukung aplikasi WLAN melalui SPI bus untuk berkomunikasi dengan microcontroler host atau processor yang lainnya [6]. Dengan clock $26 \mathrm{MHz}$ dan mendukung enkripsi 64-128 bit WEP, TKIP, dan AES menjadikan chipset ini sangat aman digunakan. Kemudian chipset ini juga mendukung standarisasi RF transceiver IEEE $802.11 \mathrm{~b} / \mathrm{g}$ sehingga tidak menyebabkan interference bagi yang lain.

\subsection{Optocoupler}

Dalam elektronik, optocoupler atau photocoupler adalah komponen yang mentransfer sinyal listrik antara dua sirkuit yang terisolasi dengan menggunakan cahaya. Optocoupler biasanya digunakan untuk mencegah tegangan tinggi yang dapat mempengaruhi sistem penerima sinyal. Jenis umum dari optocoupler terdiri dari sebuah LED dan phototransistor dalam tempat yang sama. Jenis lain dari kombinasi LED dan Photo dioda, LED dan LASCR, dan pasangan LED - 
Photoresistor. Optocoupler biasanya digunakan untuk mengirimkan sinyal digital antar 2 buah sistem yang berbeda, namun dengan menggunakan teknik-teknik tertentu optocoupler juga memungkinkan untuk digunakan dalam pengiriman sinyal analog. Pada sistem ini digunakan sebuah sensor yang merupakan optocoupler dari jenis LED-PhotoTransistor sehingga pembahasan berikut hanya membahas mengenai masalah LED dan Transistor saja [7].

\subsection{IP (Internet Protocol) Address}

IP Address adalah deretan angka biner antara 32-bit sampai 128-bit yang dipakai sebagai alamat identifikasi untuk tiap komputer host dalam jaringan internet. Panjang dari angka ini adalah 32-bit (untuk IPv4 atau IP versi 4) dan 128-bit (untuk IPv6 atau IP versi 6) yang menunjukkan alamat dari komputer tersebut pada jaringan internet berbasis TCP/IP.

IPv4 (IP versi 4) adalah sebuah jenis pengalamatan jaringan yang digunakan di dalam protokol jaringan TCP/IP yang menggunakan protokol IP versi 4. Panjang totalnya adalah 32-bit dan secara teoritis dapat mengalamati hingga 4 miliar host komputer atau lebih tepatnya 4.294.967.296 host di seluruh dunia, jumlah tersebut didapatkan dari 256 (didapatkan dari 8 bit) dipangkat 4(karena terdapat 4 oktet) sehingga nilai maksimal dari alamat IP versi 4 tersebut adalah 255.255.255.255 dimana nilai dihitung dari nol sehingga nilai host yang dapat ditampung adalah $256 \times 256 \times 256 \times 256=4.294 .967 .296$ host, bila host yang ada di seluruh dunia melebihi kuota tersebut maka dibuatlah IP versi 6 atau IPv6. Contoh alamat IP versi 4 adalah 192.168.0.3.

\subsection{WiFi}

WiFi adalah sebuah teknologi yang memanfaatkan peralatan elektronik untuk bertukar data secara nirkabel (menggunakan gelombang radio) melalui sebuah jaringan komputer, termasuk koneksi internet berkecepatan tinggi [8]. Titik akses (atau hotspot) seperti itu mempunyai jangkauan sekitar 20 meter di dalam ruangan dan lebih luas lagi di luar ruangan. Agar terhubung LAN WiFi, sebuah komputer perlu dilengkapi dengan pengontrol antarmuka jaringan nirkabel. Gabungan komputer dan pengontrol antarmuka disebut stasiun. Semua stasiun berbagi satu saluran komunikasi frekuensi radio. Transmisi di saluran ini diterima oleh semua stasiun yang berada dalam jangkauan. Sebuah alat WiFi dapat terhubung ke internet ketika berada dalam jangkauan sebuah jaringan nirkabel yang terhubung ke internet.

Router yang melibatkan modem jalur pelanggan digital atau modem kabel dan titik akses WiFi, biasanya dipasang di rumah atau bangunan lain, menyediakan akses internet dan antar jaringan ke semua peralatan yang terhubung dengan router secara nirkabel. WiFi dirancang berdasarkan spesifikasi IEEE 802.11 , ada empat varian dari 802.11 yaitu:
a. $802.11 \mathrm{a}$
b. $802.11 \mathrm{~b}$
c. $802.11 \mathrm{~g}$
d. $802.11 \mathrm{n}$

Adapun spesifikasi dari WiFi sebagai berikut:

Tabel 1. Spesifikasi WiFi

\begin{tabular}{ccc}
\hline Spesifikasi & Kecepatan & $\begin{array}{c}\text { Frekuensi } \\
\text { Band }\end{array}$ \\
\hline $802.11 \mathrm{~b}$ & $11 \mathrm{Mb} / \mathrm{s}$ & $\sim 2.4 \mathrm{GHz}$ \\
$802.11 \mathrm{a}$ & $54 \mathrm{Mb} / \mathrm{s}$ & $\sim 5 \mathrm{GHz}$ \\
$802.11 \mathrm{~g}$ & $54 \mathrm{Mb} / \mathrm{s}$ & $\sim 2.4 \mathrm{GHz}$ \\
$802.11 \mathrm{n}$ & $100 \mathrm{Mb} / \mathrm{s}$ & $\sim 2.4 \mathrm{GHz}$ \\
\hline
\end{tabular}

Secara teknis operasional, WiFi merupakan salah satu varian teknologi komunikasi dan informasi yang bekerja pada jaringan dan perangkat WLAN (Wireless Local Area Network).

\section{Hasil dan Pembahasan}

Penerapan sistem membahas hasil dari penerapan teori yang telah berhasil penulis kembangkan sehingga menjadi sistem tersebut dapat berjalan sesuai dengan perancangan 
awal. Berikut ini adalah foto hasil penerapan dari perancangan sistem terlihat pada gambargambar di bawah ini :

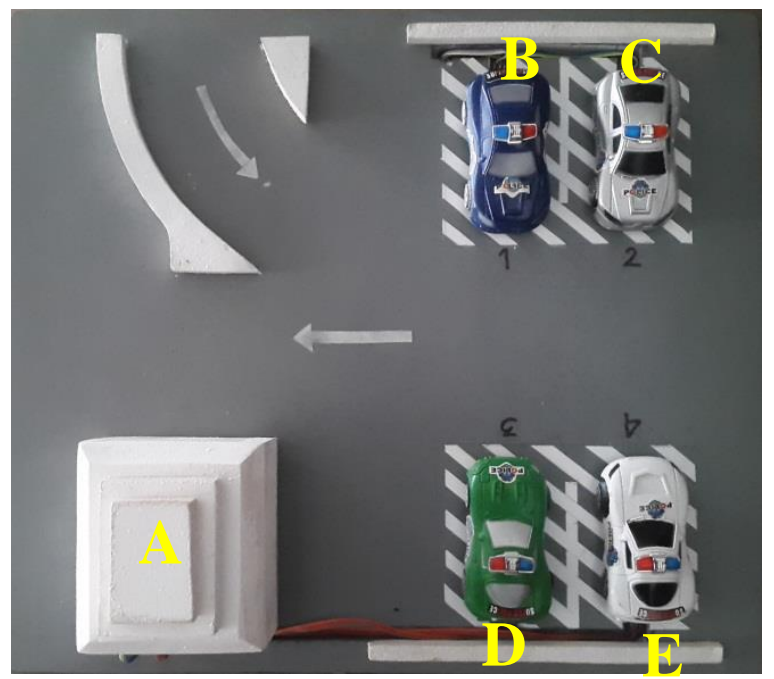

Gambar 4. Rangkaian Web server tampak atas
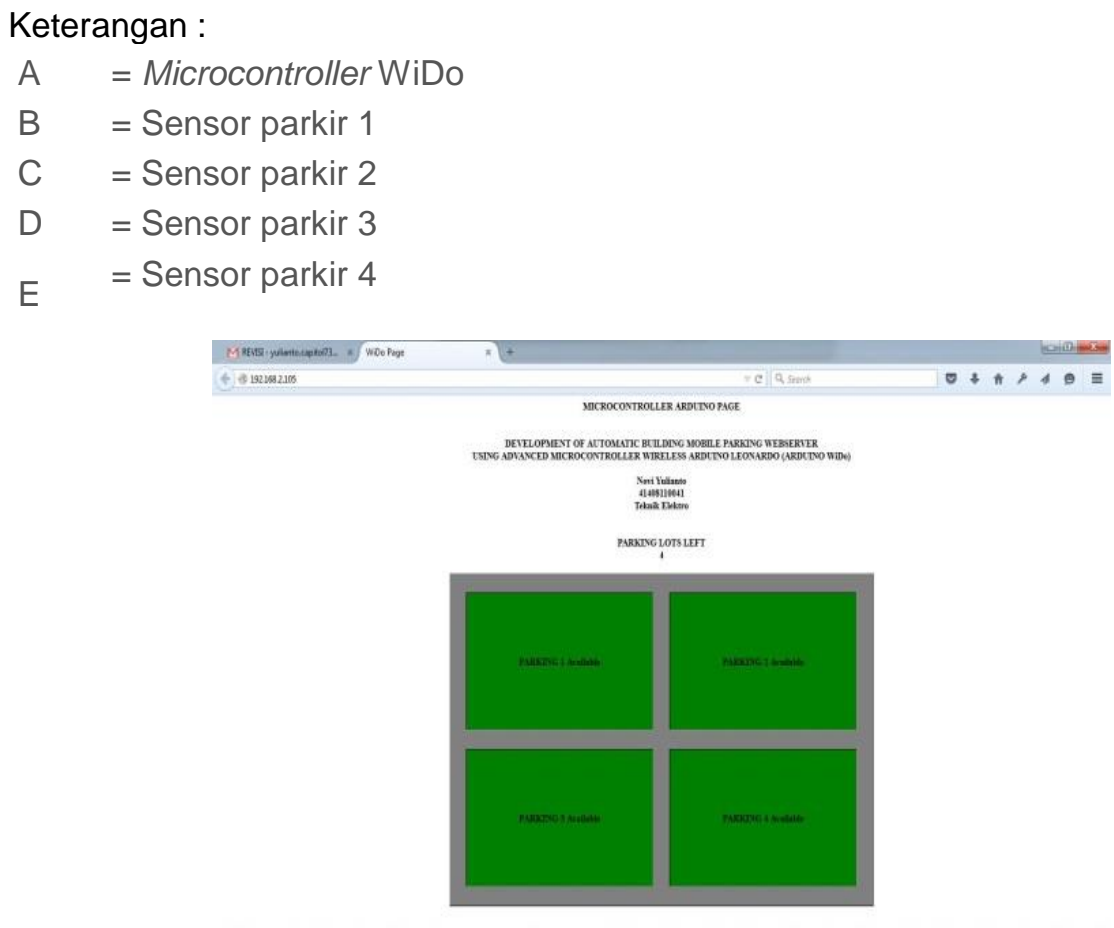

Gambar 5. Tampilan Web server Pada Browser Chrome

\section{Kesimpulan}

Setelah melakukan perancangan, penerapan dan pengujian terhadap sistem, maka dapat ditarik beberapa kesimpulan dan saran sebagai berikut : Microcontroller WiDo mampu untuk memberikan informasi kepada pengguna mengenai keadaan tempat parkir secara real time serta dengan menggunakan module sensor optocoupler yang diposisikan sebagai sensor parkir sebagai komponen input dari sistem, microcontroller WiDo mampu untuk membaca kondisi 
lingkungan analog yaitu ada atau tidaknya mobil pada tempat parkir, kemudian mengubahnya menjadi data-data elektronik yang kemudian digunakan untuk pengendalian peralatan elektronik lainnya. Microcontroller Arduino Wido memberikan kemudahan pemasangan sistem dengan menggantikan fungsi kabel dengan menggunakan fungsi wireless untuk pengendalian dan monitoring peralatan-peralatan listrik baik di rumah-rumah tangga maupun di gedunggedung perkantoran

\section{Daftar Pustaka}

[1] M. Kagum, "Perancangan Sistem Monitoring dan Pengendalian Suhu Via Wireless Webserver berbasis Microcontroller WiDo," Fakultas Teknik Universitas Mercubuana. Jakarta--Indonesia, 2015.

[2] V. Liao, "Technical Data Sheet Opto Interrupter." Everlight Electronics Co., Ltd., Taipei, pp. $1-9,2009$.

[3] "WiDo - Open Source IoT Node (Arduino Compatible) Schematic." DFRobot.com, Shanghai, 2015.

[4] "Datasheet AVR Microcontroller ATMega32U4." Atmel Corporation, 2010.

[5] "Datasheet LM78XX 3-Terminal 1A Positive Voltage Regulator." Fairchild Semiconductor Corporation, 2013.

[6] "Datasheet WG1300-B0 WLAN Module TI CC3000 IEEE 802.11b/g solution." JORJIN TECHNOLOGIES INC, China, 2012.

[7] "Schematic Line Follower Sensor." Everlight Electronics Co., Ltd, Taipei, 2005.

[8] R. Lesniak, "Adafruit CC3000 WiFi." Adafruit Industries, Newyork, 2015. 